\title{
RACIONALIDADE ECONÔMICA, TRABALHO E ECOLOGIA EM ANDRÉ GORZ
}

\author{
André Langer*
}

\begin{abstract}
O presente artigo tem por objetivo apresentar a análise crítica de André Gorz sobre o trabalho e a ecologia política a partir da centralidade que o conceito de racionalidade econômica no capitalismo adquire em seu pensamento. Para ele, a extensão ilimitada da racionalidade econômica ao trabalho e à natureza é considerada sem futuro do ponto de vista da sociedade. Gorz reconhece a íntima relação entre a crítica do capitalismo e a tarefa da ecologia política. Outro aspecto presente em sua obra, menos explorado, é a relação entre trabalho e crise ecológica. O capitalismo apropria-se do trabalho ou emprego não apenas para os seus interesses, mas também os transforma em instrumentos de destruição da natureza. Este paper objetiva também, fiel ao espírito do próprio Gorz, embora de maneira sucinta, indicar alguns horizontes alternativos.

PAlavras-chave: Gorz. Racionalidade econômica. Trabalho. Ecologia política. Capitalismo.
\end{abstract}

"Nós sabemos que o nosso modo de vida não tem futuro" (Gorz, 1978, p. 18). Essa sentença sobre a nossa civilização não foi pronunciada ontem, mas em meados da década de 70 do século passado. Ela revela uma análise aguda do nosso modo de produzir e de consumir, que moldou um estilo de vida e está se mostrando sem futuro. De lá para cá, ela, infelizmente, não apenas não foi desmentida, como está sendo confirmada pelas subsequentes pesquisas e pela observação de fenômenos naturais e sociais.

O Relatório do IPCC (Painel Intergovernamental sobre Mudanças Climáticas) de 2007, órgão vinculado à Organização Mundial das Nações Unidas (ONU) e que reúne cientistas do mundo inteiro, somente vem confirmar o que já era perceptível a olho nu. Nele aparecem duas fortes evidências: a primeira, de que o aquecimento global é "inequívoco"; e a segunda, de que ele se deve à interferência humana. A ação humana sobre a Terra, no entanto, não se dá de forma direta, mas mediada

* Faculdade Vicentina - FAVI.

Av. Jaime Reis, 531A. Alto São Francisco. Cep: 80510-010 Curitiba - Paraná - Brasil andrelanger15@gmail.com por um sistema (o capitalismo), que privilegia uma determinada racionalidade (econômica, instrumental), com vistas a um optimum: a obtenção do máximo de lucro. O resultado é um círculo vicioso que implica a dominação da natureza e a exploração humana através da técnica e do trabalho.

Por isso, na perspectiva de Gorz, a superação da presente crise só se dá pela crítica da racionalidade econômica, ou seja, pela crítica do capitalismo e do trabalho. Quanto a esse aspecto, o autor é considerado um pioneiro, por vincular uma crítica à outra. É preciso ressaltar que sua análise crítica do trabalho se situa numa perspectiva mais ampla, a qual envolve não apenas a economia, mas, fundamentalmente, a sociedade. O horizonte último de Gorz não é a economia, tampouco o capitalismo, mas a sociedade. Ele propugna uma inversão que coloque novamente a sociedade no centro e, portanto, as pessoas, seu "bem viver", a qualidade de vida e o pleno desenvolvimento de todas suas potencialidades. O ponto de chegada deve ser uma sociedade desalienada. Trata-se de um projeto de sociedade que implica também uma nova antropologia capaz de 
superar o redutor homo economicus e abra espaço para um ser humano com DNA marcado pela convivialidade. Portanto, nas reflexões de Gorz, três campos sempre estão, de uma ou de outra maneira, relacionados: economia, ecologia e sociedade.

A perspectiva inovadora do pensador reside no fato de que ele coloca o trabalho, entendido como princípio organizador de nossa vida e de todo o corpo social, no centro de uma relação com três termos: "instrumento de transformação da natureza, ele [o trabalho] estrutura as nossas sociedades democráticas nos últimos três séculos” (Gollain, 2000, p. 7, grifo do autor). Sendo assim, o trabalho "constitui um objeto privilegiado da crítica de uma ecologia política preocupada com a dupla exploração da natureza e do ser humano, inaugurada pelo capitalismo" (Gollain, 2000, p. 7).

Parte das análises de Gorz centra-se na crítica da sociedade capitalista do crescimento. O capitalismo constitui-se em "um sistema social cujos aparelhos e processos de produção e de reprodução autonomizados ameaçam a existência individual até nas bases naturais da vida" (Gorz, 1991, p. 23). A "produção de mercadorias" esbarra em limites físicos intransponíveis, o que leva à constatação de que "o capitalismo de crescimento está morto, assim como a sociedade de crescimento" (Gorz, 1978, p. 17). inevitavelmente pela crítica do trabalho. Uma das características de nosso autor é que ele não se detém nem se contenta apenas com a análise, por mais aguda e interessante que seja. Ela se insere na perspectiva de propor alternativas. Assim, embora de maneira sucinta, indicamos alguns dos seus horizontes alternativos.

$\mathrm{O}$ artigo se divide em três partes. A primeira concentra-se na revolução representada pelo surgimento da civilização tecnocientífica e na crise de reprodução que ela implica. A segunda analisa a racionalidade econômica no contexto da "invenção" do trabalho. Consideramos ser essa a parte central da reflexão. O conceito de racionalidade econômica, embora desenvolvido tardiamente, é fundamental para dimensionar corretamente as reflexões de Gorz sobre a ecologia política e o trabalho. A terceira parte, finalmente, propõe, sempre a partir das reflexões do pensador francês, perspectivas de convivência em sociedade e em harmonia com a natureza. O denominador comum é sempre a limitação da racionalidade econômica.

\section{A CIVILIZAÇÃO TECNOCIENTÍFICA}

O Ocidente pode ser lido como aquele segmento que realizou, inicialmente, uma mutação na maneira de conceber e de fazer ciência. O conhecimento científico perseguido pela ciência moderna significou uma ruptura com a "ciênciacontemplação", tornando-se menos intervencionista no mundo e mais propenso a compreender as leis naturais e os fenômenos sociais.

Ainda no final do século XVI, Francis Bacon defendia apaixonadamente uma finalidade prática para a ciência, ao desejar sua vinculação com a "indústria". Dedicava-se à afirmação da ideia "de que o saber devesse produzir seus frutos na prática, de que a ciência devesse ser aplicável à indústria, de que os homens tivessem o dever sagrado de se organizarem para melhorar e para transformar as condições de vida" (Bacon, 1620 apud De Masi, 1999, p. 12). 
A grande originalidade da ciência moderna está em que se "propôs não apenas a compreender o mundo ou explicá-lo, mas também transformá-lo" (Santos, 2004, p. 18). Dessa maneira, a ciência moderna quer imiscuir-se mais profundamente no mundo do que qualquer outra forma de conhecimento anterior.

O modelo da ciência não é mais a metafísica ou a retórica, mas a física, que, por sua vez, permite descobrir as causas e as possibilidades da ação transformadora [...] A ciência não tem mais por vocação descobrir a verdade, mas descobrir as causas que permitem ao homem transformar o mundo: conhecer é, de agora em diante, agir. Enfim, esta transformação é orientada não apenas para o artifício, mas, sobretudo, para o artifício útil. A relação de crença e de respeito para com a natureza é substituída por uma relação utilitária (Méda, 1995, p. 80).

Essa tríplice revolução abre caminho para uma civilização que se pretende universal e que assume ares quase prometeicos. Se a ciência moderna se caracteriza por sua utilidade, ela precisa se mostrar útil, desenvolver tecnologias ou bens que tenham serventia para as sociedades e, nesse sentido, provoquem interferências sobre elas e, mais ainda, mediante seus conhecimentos, dominem a natureza. Já o disse esplendidamente bem Descartes, ao formular, nestes termos, o "espírito" da época, cuja execução se encontrava apenas em seus elementos embrionários. Descartes (1991, p. 63) diz:

Pois elas [as noções gerais da Física] me fizeram ver que é possível chegar a conhecimentos que sejam muito úteis à vida, e que, em vez dessa Filosofia especulativa que se ensina nas escolas, se pode encontrar uma outra prática, pela qual, conhecendo a força e as ações do fogo, da água, do ar, dos astros, dos céus e de todos os outros corpos que nos cercam, tão distintamente como conhecemos os diversos misteres de nossos artífices, poderíamos empregá-los da mesma maneira em todos os usos para os quais são próprios, e, assim, nos tornar como que senhores e possuidores da natureza.

A ciência se desenvolve vertiginosamente, abrindo campos e possibilidades inauditos ao gênio e à ação humanos. Mas ela é guiada por uma lógica ou uma racionalidade que pri- vilegia um viés econômico ou instrumental. Dessa maneira, "a escolha das técnicas, portanto, o sentido em que elas evoluem, é sempre motivada pela preocupação de assegurar ao capital o máximo de poder e de controle" (Gorz, 2000, p. 223) sobre a natureza e o trabalho humano. Historicamente, o projeto humano sempre esteve duplamente marcado: "o projeto de domínio e apropriação da natureza e, ao mesmo tempo, um projeto de controle do homem e da sociedade" (Gollain, 2000, p. 20).

Gradativamente, mergulhamos em sociedades cuja vida é configurada pelo paradigma tecnocrático, que é homogeneizador e unidimensional. A "totalidade da existência humana é marcada pela técnica. A realidade técnica, a produção técnica e seus produtos apresentam-se como o modelo de interpretação da totalidade do ser humano, o critério para o que deve valer como real e verdadeiro" (Oliveira, 2016, p. 131-132). A técnica alça-se à posição de nova natureza, na medida em que a "tecnosfera", produzida através da técnica moderna, substitui a "biosfera".

Manifesta-se com clareza para nós que a 'tecnosfera', produzida através da técnica moderna, se põe no lugar da 'biosfera', que o ser humano encontrou e, por sua vez, só pode ser dominada através de procedimentos tecnológicos. Considerando o significado originário entre os gregos de 'Physis' enquanto algo pré-dado, que cresce e se desenvolve por si mesmo independentemente do ser humano, é preciso dizer que temos agora uma nova natureza. O que caracteriza precisamente nossa técnica moderna é que ela se fez ciência, ou seja, se baseia num conhecimento rigoroso das forças da natureza e de suas leis de tal modo que nosso relacionamento atual com a natureza é fundamentalmente marcado pela ciência moderna (Oliveira, 2016, p. 135).

O surgimento da ciência ocidental está, pois, umbilicalmente vinculado ao "desenvolvimento tecnológico ocidental” (Morin, 1996). A lógica econômica emergente é redutora. Progresso é sinônimo de desenvolvimento econômico; desenvolvimento econômico é sinônimo de crescimento econômico; o crescimento econômico é medido pelo aumento do Produto Interno Bruto 
(PIB), que, por sua vez, pode ser verificado pelo número de empregos que cria. No entanto, a lógica da quantificação, da matematização, da dominação, revela-se astuta. O progresso é, por natureza, cumulativo e linear, e se traduz de forma quantitativa em detrimento da qualidade.

Essa racionalidade quantificável do desenvolvimento

[...] é irracional. O desenvolvimento ignora que o crescimento técnico-econômico produz subdesenvolvimento moral e psíquico: a hiperespecialização generalizada, a compartimentalização em todas as áreas, o hiperindividualismo e o espírito do lucro geram a perda da solidariedade. O desenvolvimento engendra um conhecimento especializado que é incapaz de compreender os problemas multidimensionais (Morin, 2002, p. 45).

A ecologia política tem como uma de suas tarefas questionar tal concepção de progresso e de desenvolvimento. Um pensamento complexo deve propor progressos também no nível do espírito, não apenas das técnicas ou dos meios de produção. Ou, como diz Morin (1996, p. 98) com certa ironia, "há que fazer um progresso na ideia de progresso”. Reconhecer certas ignorâncias e limites pode ser um progresso na ciência, ao contrário do que se pensava anteriormente.

A noção de progresso, portanto, parece ter perdido seu rumo. Prometeu desenvolvimento integral e entregou crescimento econômico. Vendeu (e continua a vender) a ilusão de que "mais é sempre melhor" ou "quanto mais, melhor" (Gorz, 2003). Em vista desse crescimento contínuo e ilimitado, foram se desenvolvendo uma série de técnicas, produtos e consumos tendo em vista, em primeiro lugar, atender às necessidades de acumulação do capital. "É preciso que quantidades crescentes de capital sejam investidos com lucro, o que exige o consumo de um fluxo crescente de mercadorias e de serviços mercantis". Para que isso funcione, é preciso induzir "a população a satisfazer suas necessidades com um máximo de consumo e suscitar um máximo de necessidades de consumo mercantis” (Gorz, 1991, p. 172).

\section{CONFLITOS DE REPRODUÇÃO DO CAPITALISMO}

O capitalismo, como sistema, apresenta uma capacidade de reprodução que, por sua dinâmica autonomizada, entra em conflito com a dinâmica da natureza e da humanidade (Beaud, 1997). O capitalismo, informado por uma lógica racional instrumental e marcado pela ânsia de domínio, entranha um conflito de reprodução social, longa e profundamente explorado em suas diversas facetas pelas mais diversas ciências sociais. Quando falamos que o capitalismo se volta contra a humanidade, corremos o risco de uma generalização apressada e incorreta. Por um lado, o capitalismo apresenta uma enorme capacidade de criar riquezas e mercadorias, além de mobilizar, com essa finalidade, poderosos meios técnicos, intelectuais, materiais e financeiros. Por outro, apresenta uma enorme capacidade de ignorar a pobreza e a miséria e de transformar paisagens, sociedades, normas e valores. Os seres humanos não estão colocados da mesma maneira diante desse sistema e não contam com os mesmos recursos para enfrentar suas adversidades. Seria mais correto postular que uma pequena parcela da humanidade, que tem o controle da "máquina capitalista", usufrui das benesses oferecidas por esse modo de produção e de consumo, em detrimento da exploração, dominação e exclusão do restante da população mundial (Beaud, 1997). A problemática da fome no mundo, o tratamento dado às migrações, o trabalho e suas condições e as desigualdades sociais passam por essa questão.

Outro conflito se dá entre a reprodução do capitalismo (e de parte da Humanidade ligada às suas necessidades e a seus produtos) e a reprodução do planeta. A especificidade do capitalismo consiste em que "somente ele dispõe de uma capacidade de autorreprodução que podemos qualificar como forte, capacidade que permite compreender as disjunções cada vez mais profundas que observamos entre economia e sociedade" (Beaud, 1997, p. 
81). A tendência do capitalismo é de autorreproduzir-se de forma autônoma em relação ao meio ambiente e às sociedades.

O capitalismo procura desvincular seu tempo do tempo da natureza:

Com o advento do modo de produção capitalista, fundado sobre a lógica da acumulação, que exige a exploração da maior quantidade possível de matérias-primas, de energia e de trabalho humano no menor tempo possível para produzir o maior número possível de riquezas para o mercado, um umbral foi transposto para além do qual a temporalidade da história humana impôs-se sobre a temporalidade natural (Gollain, 2000, p. 23).

A consequência natural desse processo, cujo objetivo é o crescimento indefinido de riquezas, é a "transposição dos limites” (Gollain, 2000, p. 23) físicos do mundo natural ao qual estamos vinculados. A velocidade das mudanças provocadas pela humanidade com o uso de tecnologias que resistem se submeter ao tempo e ao espaço afeta, ao mesmo tempo, o meio ambiente e os pobres.

Mas, como lembra com justiça Gorz, “a atividade humana encontra na natureza seu limite externo" (Gorz, 1978, p. 19), uma vez que "as sociedades industrializadas vivem da pilhagem acelerada dos estoques, cuja constituição demandou dezenas de milhões de anos" (Gorz, 1978, p. 18). A vontade desenfreada de crescimento econômico, alimentada pelo consumismo, encontra um limite inimaginável até poucas décadas atrás: a capacidade física de o Planeta Terra repor, na mesma velocidade requerida pelo capitalismo, os recursos necessários para satisfazer todos os caprichos de consumo de uma pequena parcela da população mundial. Essa capacidade foi ultrapassada.

O ecossistema natural possui uma capacidade autogeradora e autorreorganizadora que, devido às suas extremas diversidade e complexidade, permite-lhe autorregular-se e evoluir para uma complexidade e uma diversidade crescentes. Essa capacidade de autorregeneração e de autorreorganização é prejudicada por técnicas que tendem a racionalizar e a dominar a natureza, a torná-la previsível e calculável. (Gorz, 2010, p. 25)
O crescimento econômico torna-se um objetivo buscado por si mesmo. Ele é, para o capitalismo, "uma necessidade sistêmica totalmente independente e indiferente à realidade material daquilo que cresce. Ele responde a uma necessidade do capital” (Gorz, 2005, p. 7).

O crescimento econômico, que deveria assegurar a abundância e o bem-estar a todos, faz crescer as necessidades mais rapidamente que sua satisfação, e leva a um conjunto de impasses que não são apenas econômicos: o capitalismo de crescimento está em crise não apenas porque é capitalismo, mas também porque é de crescimento (Gorz, 1978, p. 18).

Por essas razões, Gorz está convencido de que tanto o capitalismo de crescimento como a sociedade de crescimento não têm futuro. Segundo ele, é preciso perguntar-se pelo sentido do crescimento e seu conteúdo. De que crescimento nossas sociedades têm realmente necessidade? Isso porque, para a ciência econômica, interessa apenas o crescimento que ajuda a fazer crescer o PIB, isto é, "o aumento da quantidade de dinheiro trocado, a quantidade de mercadorias compradas e vendidas no decurso de um ano, quaisquer que sejam essas mercadorias" (Gorz, 2005, p. 4).

Karl Polanyi (2000), em sua clássica obra A grande transformação, recorrendo a uma perspectiva histórica, mostra que, em sociedades anteriores à nossa, os sistemas econômicos foram organizados não segundo uma economia de mercado, nem com vistas única e primeiramente à obtenção do lucro obtido mediante a racionalização dos meios de produção e de organização do trabalho. Ao contrário, "os costumes e a lei, a magia e a religião cooperavam para induzir o indivíduo a cumprir as regras de comportamento, as quais, eventualmente, garantiam o seu funcionamento no sistema econômico" (Polanyi, 2000, p. 75).

Mas, a partir do século XVI, os mercados passaram progressivamente a ser mais numerosos e importantes e se constituíram como um mercado autorregulável que, por sua vez, foi lentamente corroendo as demais lógicas e seus valores, para impor os seus. Uma gran- 
de transformação se impôs e que consiste no seguinte: "em vez de a economia estar embutida nas relações sociais, são as relações sociais que estão embutidas no sistema econômico" (Polanyi, 2000, p. 77). A consequência desse processo é que, em definitivo, "[...] a sociedade humana torna-se um acessório do sistema econômico" (Polanyi, 2000, p. 97). Aqui se encontra o cerne daquilo que Polanyi chama de "grande transformação". Em tal contexto, a devastação da terra não se apresenta como uma fatalidade, mas "a consequência de um modo de produção" que "exige a maximização dos rendimentos e recorre a técnicas que violam o equilíbrio biológico” (Gorz, 2010, p. 10).

\section{A mundialização da produção, das trocas e da co- municação e, sobretudo, do poder inaudito sobre a natureza, fruto do desenvolvimento tecnológico, conferem à humanidade [...] um estatuto de força geológica planetária (Gollain, 2000, p. 23).}

Estudos realizados já nos anos 1960 começam a questionar o futuro e a sobrevivência de um sistema de crescimento indefinido e de expansão ilimitada das mercadorias em um mundo físico limitado. Economistas, como Serguei Podolinsky, Georgescu-Roegen e, mais recentemente, Herman Daly, entre outros, têm o atrevimento de questionar, com base em pesquisas da física, os fundamentos da ciência econômica. Resulta que 今. os fundamentos da ciência econômica assentam ㄱ sobre "analogias e metáforas da mecânica clássi(Cechin, 2010, p. 34).

Estando a estrutura analítica do paradigma dominante na ciência econômica baseada na metáfora da conservação de energia, disso decorre uma visão de economia tida como uma totalidade. A economia é vista como um circuito fechado em que nada entra e nada sai, ou seja, desenvolve um metabolismo em que não há entradas (de matéria e energia), nem saídas (resíduos). Está em permanente equilíbrio. Com essas características, a economia se apresenta como uma "máquina de moto-perpétuo, uma máquina capaz de produzir trabalho ininterruptamente, consumindo a mesma energia e valendo-se dos mesmos materiais. Tal máquina seria um reciclador perfeito" (Cechin, 2010, p. 41).

No entanto, há aqui um equívoco: "isso contradiz uma das principais leis da física: a segunda lei da termodinâmica, a lei da entropia" (Cechin, 2010, p. 41). De acordo com essa lei, a energia é dissipativa e, portanto, em qualquer processo de produção, há sempre perdas - a quantidade de energia que entra em qualquer processo não é a mesma que sai.

Essas descobertas no campo da física e da química são fundamentais para a compreensão de qualquer atividade econômica e, mais ainda, para a detecção dos limites da economia capitalista. Emerge uma visão, essa sim real, de que "a economia não é uma totalidade, mas, sim, um subsistema de um sistema maior" (Cechin, 2010, p. 41), o ecossistema. O metabolismo social deve estar referido ao metabolismo da natureza, deve abrir-se a ele; caso contrário, entrará em conflito com ele. O sistema econômico, como qualquer outro sistema, está sujeito às leis da termodinâmica, e precisa levar em consideração essa dependência, isto é, precisa incorporar os cálculos da entropia nos processos de produção.

O capitalismo procedeu a uma separação entre a reprodução material da sociedade e o ecossistema, mas se esqueceu de que não é possível produzir coisa alguma do nada. A produção econômica é obrigada a gastar recursos naturais e a produzir resíduos. Mas, como faltou à ciência econômica essa visão mais abrangente, considerou que

[...] o sistema se reproduz se houver um fluxo suficiente de bens de consumo e bens de capital sendo produzidos e circulando na economia. Capital 
e trabalho são os únicos fatores de produção nesses esquemas analíticos, assim, não foi atribuída nenhuma importância para o papel da natureza na explicação da dinâmica capitalista, nem como fonte provedora de recursos, nem como sumidouro de resíduos (Cechin, 2010, p. 43).

A utilização da metáfora mecânica aplicada à economia foi responsável por uma compreensão do processo de produção como um sistema isolado, a-histórico e que não sofre de interferências externas. Sobre essa base irreal se assenta a visão de um crescimento econômico infinito.

\section{A INVENÇÃO DO TRABALHO}

Gorz debruça-se a destrinchar a racionalidade econômica que deu origem e sustentação ao paradigma moderno de economia, com as características e impactos que acabamos de ver. Como a racionalidade econômica está estreitamente vinculada à concepção de trabalho a que ela dá origem, vamos, primeiramente, nos deter a analisar as mudanças que ela opera na atividade que, de um modo geral, denominamos de trabalho.

Em nossas sociedades, o trabalho foi alçado a fator estruturante da organização econômica, política e social. Ele se tornou um "fato social total”, pois "estrutura não somente a nossa relação com o mundo, mas também as nossas relações sociais. O trabalho é a relação social fundamental. Está, além disso, no centro da visão de mundo que é a nossa" (Méda, 1995, p. 26).

Uma análise histórica, no entanto, nos leva a perceber que aquilo que comumente chamamos de "trabalho" nem sempre existiu. As sociedades pré-modernas não tinham a mesma relação e concepção do que nós, hoje, chamamos de trabalho. E nem ele ocupava o mesmo lugar que tem para nós. O que nós nos acostumamos a chamar de “trabalho' é uma invenção da modernidade. ${ }^{1} \mathrm{~A}$ forma sob a qual

${ }^{1}$ Sobre a temática da "invenção" do trabalho pela modernidade, cf. Gorz (2003, p. 21-31), Méda (1995, p. 60-91), Gollain (2000, p. 109-122). o conhecemos e praticamos, aquilo que é o cerne de nossa existência individual e social, foi uma invenção, mais tarde generalizada com o industrialismo" (Gorz, 2003, p. 21).

A natureza do trabalho passou por uma profunda mutação, que alterou sua compreensão, suas características e seu lugar social. A atividade, feita com vistas à satisfação das necessidades vitais, transmutou-se em atividade produtora de mercadorias, em trabalho abstrato. É esse tipo de trabalho que "se tornou a principal fonte de renda que permite aos indivíduos viver, mas que é também uma relação social fundamental [...] e finalmente o meio para alcançar a abundância” (Méda, 1995, p. 8).

Pelo fato de propor que o trabalho seja uma criação do capitalismo, não se quer, evidentemente, afirmar que aquelas atividades realizadas em vista da subsistência física, do atendimento das necessidades básicas da vida individual e social - o que hoje chamamos de trabalho -, não tenham existido. Nessa acepção, o "trabalho" sempre existiu, embora com outras feições nas sociedades pré-capitalistas.

Antes de examinar a transformação na natureza do trabalho operada pelo capitalismo e suas consequências, vamos nos deter a indicar sucintamente os elementos centrais das concepções de trabalho anteriores ao surgimento da modernidade.

Primeiramente, convém recordar que as chamadas sociedades pré-capitalistas ${ }^{2}$ não são sociedades sem trabalho. Mas não são sociedades estruturadas pelo trabalho. Elas não conhecem categorias como economia e trabalho, pelo menos não na concepção da ciência moderna. As pesquisas antropológicas, de grande ajuda para a compreensão do lugar social do trabalho nas sociedades estudadas, concluem que é impossível encontrar, nessas sociedades, um significado semelhante ao termo trabalho. Algumas sociedades nem mesmo têm uma palavra que distingue as atividades produtivas dos outros comportamentos humanos (Méda, 1995).

\footnotetext{
${ }^{2}$ Para esse tópico, salvo indicação em contrário, nos fundamentamos em Méda (1995, p. 30-59).
} 
A ideia de necessidades ilimitadas está ausente nessas sociedades, assim como a ideia de acumulação ou de produção acima do necessário para a satisfação das necessidades. Além disso, elas não conhecem o exercício individual ou com intenções puramente individuais da atividade produtiva. Por isso, também o tempo consagrado ao aprovisionamento ou às atividades de reprodução da força física é o mínimo possível. Em suma, "o sistema econômico estava submerso em relações sociais gerais; os mercados eram apenas um aspecto acessório de uma estrutura tradicional controlada e regulada mais do que nunca, pela autoridade social” (Polanyi, 2000, p. 88). Ou então, os fatos sociais que estruturam essas sociedades não têm uma natureza econômica.

Também entre os gregos não é possível encontrar algo que unifique as atividades produtivas. Entre eles, encontramos uma hierarquia muito rígida na classificação das múltiplas atividades humanas, que são valorizadas em função da maior ou menor semelhança que podem ter com a imobilidade e a eternidade. Hannah Arendt (1989) faz uma distinção entre vita contemplativa e vita activa. A primeira caracteriza-se pela valorização do pensamento, da contemplação ou da ciência. Já a vita activa pode ser dividida em dois grandes ramos de atividades: um primeiro, que abarca a atividade os gregos, dizia respeito à luta pela sobrevivência física do corpo. Ele estava associado ao seu processo biológico. Havia uma estreita relação entre produção e consumo. Tudo o que é produzido pelo labor é destinado ao consumo imediato, motivo pelo qual não deixa nada atrás de si e é, por isso mesmo, marcado pelo efêmero. Já o "work” (obra) é uma atividade inerentemente solitária e requer a maestria do uso das mãos para produzir objetos que não são intrínsecos ao ciclo vital da espécie. Através dessas atividades, os humanos fabricam uma infinidade de coisas que os rodeiam e passam a constituir a sua mundanidade. A obra combina permanência e liberdade.

Os gregos, além disso, faziam uma rígida distinção entre a esfera privada e a esfera pública. "A esfera privada, aquela da família, confundia-se, pois, com a esfera da necessidade econômica e do trabalho, ao passo que a esfera pública, política, aquela da liberdade, excluía rigorosamente as atividades necessárias ou úteis dos 'assuntos humanos"' (Gorz, 2003, p. 23), o que reforçava a ideia da superioridade da atividade política em relação ao "trabalho". "Servil e restrito ao doméstico, o 'trabalho', longe de conferir uma 'identidade social', era algo que pertencia à existência privada e excluía da esfera pública aquelas e aqueles que a ele se viam assujeitados" (Gorz, 2003, p. 24). Além disso, e esse é um aspecto importante na análise de Gorz, para os gregos, "a esfera do consumo e das necessidades materiais tem um lugar limitado, porque, para eles, as necessidades são limitadas [...], a ideia de felicidade não vem da satisfação de uma série limitada de necessidades" (Méda, 1995, p. 46).

Como se pode ver, também nessa civilização, não encontramos um termo que unifique e dê o significado daquilo que chamamos "trabalho", embora ele já se apresente como uma atividade distinta de outras atividades.

O século XVIII europeu é testemunha

labor e trabalho. A tradução é imprecisa porque, no português, o termo trabalho (do francês "travail") corresponde originalmente ao que Arendt chama de "labor" e não ao que ela chama de "work", cujo correspondente seria obra. 
de uma revolução de valores, de uma "grande transformação" (Polanyi, 2000) ou ainda de uma "brutal inversão da ordem de valores" (Méda, 1995, p. 74), da qual emergem, entre outras coisas, a concepção e o lugar social conferido ao trabalho em nossas sociedades.

O esforço de reflexão de Adam Smith contribui para a análise das bases da modernidade. O mundo moderno concede à "economia o lugar privilegiado de encontro entre os espaços privado e público, bem como o principal campo de configuração das relações sociais" (Mercure, 2005, p. 115). O "trabalho foi alçado ao patamar de valor fundamental", e o "vínculo social não é mais considerado como o produto de um pacto social, mas como o resultado de uma harmonia não intencional dos interesses" (Mercure, 2005, p. 116). O trabalho é, para Smith e doravante, essa "[...] potência humana e/ou 'maquínica' que permite criar valor” (Méda, 1995, p. 62).

Os novos fundamentos do mundo moderno são constituídos pela emergência da economia e, dentro dela, da transformação das atividades humanas em criação de valores, em que elas próprias são transmutadas em mercadorias e submetidas à marca do tempo (Méda, 1995). A evolução do conceito de trabalho encerra ainda outro aspecto de suma importância para a correta compreensão da análise crítica que Gorz faz a esse respeito: a de que, gradativamente, o trabalho é compreendido como essência do homem. A realização do homem moderno depende, em grande parte, de sua "vinculação ao trabalho, uma vez que ele passa a ser, ao mesmo tempo, fator de sobrevivência, de humanização, de integração social, de autoestima e de utilidade social" (Langer, 2004, p. 22).

Gorz (2000, p. 220) diz que o conceito de trabalho em Hegel

Designa a essência comum da totalidade das atividades pelas quais o sujeito se inscreve e se objetiva na materialidade do mundo, configura o mundo e, ao fazer isso, também produz a si mesmo. O trabalho designa a essência comum do conceber, do fazer, do fabricar e do agir, que até então eram categorias incomensuravelmente distintas.
Essa conceituação de Hegel, reconhece Gorz, é uma revolução filosófica e cultural de extraordinário alcance político. Também em Marx esse acento estará presente: "a essência do homem é o trabalho. O homem só pode existir trabalhando [...] o homem só é plenamente homem, segundo Marx, se imprimir em todas as coisas a marca da sua humanidade" (Méda, 1995, p. 100-101). Em Marx, o trabalho possui uma tríplice qualidade: "de me revelar a mim mesmo, de revelar a minha sociabilidade e de transformar o mundo" (Méda, 1995, p. 104).

Gorz debruçou-se com afinco sobre a análise dessa revolução de valores que a modernidade operou, centrando-se na temática do trabalho como fundamento do vínculo social. Para Gorz, o que chamamos trabalho não se confunde com aquilo que os gregos chamavam de labor, ou work. E diz que, se o fazemos, é num "[...] sentido radicalmente diverso do sentido que se empresta à noção de trabalho" (Gorz, 2003, p. 21). Para o capitalismo industrial, a característica mais importante desse trabalho é ser uma atividade que se realiza na esfera pública e não mais na esfera privada (Gorz, 2003).

Partindo da constatação de que o labor e a obra, entre os gregos, não gozavam de boa reputação e eram vistos como algo degradante, como um castigo, como forma de exclusão, como algo que denegria a imagem de ser humano e de cidadão, eles não podiam ser o fundamento do laço social (Langer, 2004). À luz dessa prática social, Gorz (2003, p. 22) enfatiza que o labor jamais pode ser o fundamento da coesão social, pois não é isso que ele realiza: "esse trabalho necessário à subsistência, com efeito, jamais foi fator de integração social. Era, antes, um princípio de exclusão".

O trabalho, assim como é compreendido e praticado pelo capitalismo industrial, necessita ser transformado em mercadoria, ainda que uma mercadoria muito especial, segundo Polanyi (2000), processo que faz parte da "invenção" do trabalho. Para ser mercadoria, o trabalho precisa de algumas características: 
ter preço, isto é, uma atividade passível de ser comprada e vendida em um mercado, além da possibilidade de parte da atividade humana ser destacável de seu sujeito. O trabalho aparece como “uma 'capacidade' de que o indivíduo dispõe livremente e com a qual negocia as condições de compra com um empregador" (Méda, 1995, p. 73). Emerge, portanto, um conceito de trabalho imediatamente material, quantificável e mercantil.

A característica fundamental do emprego é ser "uma atividade realizada em vista do intercâmbio mercantil e tornada necessariamente objeto de um cálculo contábil, de maneira que seja realizada o mais eficazmente possível" (Gollain, 2000, p. 112). Desse novo horizonte sociocultural nasce o trabalho entendido como emprego ou como assalariamento:

A característica mais importante desse trabalho aquele que 'temos, 'procuramos', 'oferecemos' - é ser uma atividade que se realiza na esfera pública, solicitada, definida e reconhecida útil por outros além de nós e, a este título, remunerada. É pelo trabalho remunerado (mais particularmente, pelo trabalho assalariado) que pertencemos à esfera pública, adquirimos uma existência e uma identidade sociais (isto é, uma 'profissão'), inserimo-nos em uma rede de relações e de intercâmbios, onde a outros somos equiparados e sobre os quais vemos conferidos certos direitos, em troca de certos deveres. O trabalho socialmente remunerado e determinado - mesmo 今 para aqueles e aquelas que o procuram, para aqueles outra mudança na concepção moderna de trabalho: a de que o trabalho se transmutou de "poièsis", isto é, de algo que se "faz", em algo que se "tem" (Gorz, 2004). Ter ou não ter um trabalho significa ter ou não ter um emprego e, por conseguinte, um salário. É essa dimensão que está em crise hoje, com a chamada "crise do trabalho". Pedimos desculpas por mais uma longa citação, mas ela explicita bem o que nosso autor pensa sobre essa questão.

\begin{abstract}
O 'trabalho' é definido, antes de tudo, por ser uma atividade social, destinada a inscrever-se no fluxo das trocas sociais na escala do conjunto da sociedade. Sua remuneração atesta tal inserção, mas ainda não é isso o essencial: o essencial é que o 'trabalho' preenche uma função socialmente identificada e normatizada na produção e na reprodução do todo social. E, para preencher uma função socialmente identificável, deve ser ele próprio identificável pelas competências socialmente definidas que aciona conforme certos procedimentos socialmente determinados. Ele deve, em outros termos, ser um 'ofício', uma 'profissão: isto é, a mobilização de competências institucionalmente atestadas segundo procedimentos homologados (Gorz, 2004, p. 11, grifo do autor).
\end{abstract}

Para Gorz, a sociedade do trabalho passou a identificar a forma particular de trabalho, o emprego, o assalariamento, com a forma genérica de trabalho. O emprego é sinônimo de trabalho, embora não o seja. Parte do esforço teórico de Gorz consiste em desvincular esses dois sentidos. E isso não é sem consequências, pois permite ao pensador reduzir (e não ampliar) a noção de "trabalho" entendido como emprego e, ao mesmo tempo, perceber que a noção de trabalho abre uma série de outras possibilidades sobre as quais se debruçou, especialmente em Misérias do presente, riqueza do possível.

\section{A RACIONALIDADE ECONÔMICA}

Mas como se chegou a essa situação? Como o capitalismo industrial foi capaz de "inventar" uma nova e particular noção de trabalho? Que "mágica” foi essa? Para desvendar essa revolução, Gorz analisa as origens da ra- 
cionalidade econômica. O capitalismo industrial submete o trabalho a uma racionalidade econômica cuja crítica ocupa um dos lugares centrais na análise de Gorz, desenvolvida especialmente em seu livro Metamorfoses do trabalho: crítica da razão econômica. E ele o faz recorrendo especialmente a Max Weber e Jürgen Habermas (Gorz 2003; 1991; Silva, 1999).

Para Gorz, a ideia moderna de trabalho é contemporânea do capitalismo manufatureiro. Até por volta de 1850, o capitalismo industrial ainda coexistia com a indústria doméstica na produção têxtil, ou seja, "a 'produção industrial' não era, em seu conjunto, regida pela racionalidade econômica” (Gorz, 2003, p. 24). A tecelagem era, para os tecelóes domésticos, mais do que um meio de ganhar a vida, "um modo de vida regido por tradições, respeitadas - embora pareçam irracionais do ponto de vista econômico - pelos capitalistas" (Gorz, 2003, p. 24, grifo do autor). A esses não passava pela cabeça sequer a possibilidade de racionalizar o trabalho.

No entanto, como a burguesia nascente "não pode existir sem revolucionar continuamente os instrumentos de produção e, por conseguinte, as relações de produção, portanto, todo o conjunto das relações sociais" (Marx; Engels, 1999, p. 69), esse estado de coisas está para ser transformado radicalmente. Para descrever esse momento revolucionário, Gorz transcreve um longo trecho de $A$ ética protestante e o 'espírito' do capitalismo de Max Weber. Gorz está interessado em descortinar a manobra ideológica e cultural capaz de transformar camponeses em operários. Segundo Weber, a chave está no surgimento de um "novo espírito", o "espírito do capitalismo" (Weber, 2004, p. 61). Embora, nesse momento, a forma "capitalista" já possa ser verificada em alguns casos, o "espírito" que animava esses empresários era ainda tradicionalista. Gorz conclui que a "novidade" em tudo isso não está no "interesse" que os capitalistas tinham "em racionalizar a tecelagem, dominar os custos, tornar este custo rigorosamente calculável e previsível graças à quantificação e à norma- lização de todos os seus elementos (que) nada tinha de novo", mas em que, em um determinado momento, "os produtores quiseram impô -lo a seus fornecedores”, o que se abstiveram de fazer antes (Gorz, 2003, p. 26).

Em uma análise conclusiva que recorda muito Polanyi, Gorz diz que:

\begin{abstract}
A racionalidade econômica foi por longo tempo contida, não apenas pela tradição, mas por outros tipos de racionalidade, outras finalidades e outros interesses que lhe consignavam limites a não serem ultrapassados. O capitalismo industrial só pôde desenvolver-se a partir do momento em que a racionalidade econômica emancipou-se de todos os outros princípios de racionalidade, para submetê-los a seu único domínio (Gorz, 2003, p. 27).
\end{abstract}

O “espírito do capitalismo" transgride fronteiras antes mantidas em seus limites e consiste na "sua estreiteza unidimensional, indiferente a qualquer outra consideração além da contábil, pela qual o empreendedor capitalista leva a racionalidade econômica a suas últimas consequências." (Gorz, 2003, p. 26). Segundo Weber, uma das características fundamentais da economia privada capitalista é "ser racionalizada com base no cálculo aritmético rigoroso, ser gerida de forma planejada e sóbria para o almejado sucesso econômico, contrariamente à existência do camponês" (Weber, 2004, p. 67).

Entretanto, Weber, e Gorz na sua esteira, insistem no fato de que essa racionalidade, do ponto de vista do funcionamento do sistema, da economia, pode ser profundamente "irracional" vista na perspectiva de cada indivíduo. Nem sempre o que é racional para o sistema o é para o indivíduo; e nem sempre o que faz sentido para o sistema faz sentido para o indivíduo; pelo contrário, ambos os sentidos opõemse profundamente e entram em conflito entre si. Como diz Weber, nessa nova ordem, há uma inversão segundo a qual o ser humano passa a "existir para o seu negócio e não o contrário" (Weber, 2004, p. 62. Cfr. também p. 46).

Gorz avalia que a imposição da racionalidade econômica foi "a tarefa mais difícil que 
o capitalismo industrial precisou cumprir" (Gorz, 2003, p. 29). Para isso, teve de vencer duas resistências, que envolvem, respectivamente, o modo de produzir e de consumir.

Primeiramente, o capitalismo, para impor sua racionalidade econômica, precisou constituir um mercado de trabalho. A constituição desse mercado debatia-se com o elemento "irracional" que a racionalidade econômica continha, o que Weber chamaria também de "tradicionalismo": o trabalhador "não quer 'por natureza' ganhar dinheiro e sempre mais dinheiro, mas simplesmente viver, viver do modo como habituado a viver e ganhar o necessário para tanto” (Weber, 2004, p. 53).

O capitalismo industrial precisa vencer as resistências interpostas pelo modo de vida da sociedade em meio à qual ele tenta emergir, travando uma batalha em uma dupla frente: constituir um mercado de trabalho e disciplinar o trabalhador para o regime integral e impositivo da jornada de trabalho. Ele procede à tarefa de tornar calculável tanto o custo do trabalho como seu rendimento. Além disso, transforma o trabalho - atividade por excelência - em uma grandeza material quantificável e destacável da pessoa que o executa. Dedica-se ao esforço de "distinguir o trabalho (categoria econômica quantificável) da pessoa 、 viva do trabalhador" (Gorz, 2003, p. 29). Abre, 亏े dessa maneira, o caminho para transformar o 凶ં trabalho em mercadoria. Doravante, também o đ trabalho será encontrado, negociado e trocado no mercado. E está aberto, além disso, o caminho para o trabalho abstrato, base para a compreensão da forma emprego.

A instauração do cálculo contábil é fundamental nesse processo. "Tudo pode ser calculado, e deve ser calculado, se quero ganhar" (Gorz, 2003, p. 109). O cálculo torna-se o critério supremo de avaliação. Determinada atividade vale a pena ser executada ou não, em vista do cálculo das vantagens e desvantagens, sem que se tenha em conta minhas preferências. E o cálculo é sempre o cálculo matemático, frio, imparcial, lógico. Todos os outros critérios, sociais ou pessoais são relegados a segundo plano (Langer, 2004). A vida passará a ser organizada em função desse cálculo.

Tendo presente especificamente o trabalho, Gorz (2003, p. 110-111) destaca que a predominância da racionalidade econômica se deve a duas condições: primeiro, "o trabalho deve ter por fim a troca mercantil e não o autoconsumo"; segundo, a produção "deve destinar-se à troca em um mercado livre onde produtores sem elos entre si encontram-se na qualidade de concorrentes diante de compradores com os quais não mantêm laço algum”.

Por isso, a racionalização do trabalho consistiu em uma "revolução, uma subversão do modo de vida, uma invenção de algo que nunca existira antes" (Gorz, 2003, p. 30), porque "venceu a resistência das antigas ideias de liberdade e de autonomia existenciais. Fez nascer o indivíduo que, alienado em seu trabalho, também o será em seu consumo" (Gorz, 2003, p. 31).

Em segundo lugar, a necessária produção de mercadorias necessita de sua contrapartida, o consumo. Não basta produzir de maneira mais eficiente se essa produção esbarra em uma mentalidade de uma sociedade acostumada a limitar socialmente as necessidades. Aqui se trava outra batalha de proporções gigantescas: o imperativo de transpor a natureza limitada das necessidades.

Em sociedades pré-capitalistas, "a produção destinada à troca mercantil é, em suma, regrada pelo mesmo princípio de 'suficiência' que rege a produção para o autoconsumo doméstico" (Gorz, 2003, p. 111). Em Gorz, a categoria do "suficiente" assume capital importância, pois regula o "equilíbrio entre o nível de satisfação e o volume de trabalho em si” e, como tal, "não é uma categoria econômica: é uma categoria cultural, ou existencial" (Gorz, 2003, p. 112). O suficiente é uma categoria estranha à racionalidade econômica, que, ao contrário, só "conhece as categorias do 'mais' e do 'menos", (Gorz, 2003, p. 112). O cálculo contábil "progressivamente substituiu a ordem tradicional por uma ordem formal de rigor absolutamente 
coercitivo" (Gorz, 2003, p. 112). Foi o caráter revolucionário da introdução do cálculo que permitiu "emancipar-se de toda tutela exterior e era gerador de uma ordem cujas leis objetivas não admitiam apelo" (Gorz, 2003, p. 112).

A consequência mais importante é que a racionalidade econômica "separava o trabalho de sua necessidade. A finalidade do trabalho não era mais a satisfação das necessidades" (Gorz, 2003, p. 113). O trabalhador "não produz nada do que consome e não consome nada do que produz" (Gorz, 2003, p. 30). A nova finalidade do trabalho passa a ser a de ganhar o suficiente para poder comprar as mercadorias produzidas pela máquina social. Na medida em que a paixão racionalizadora se autonomiza em relação a qualquer outra finalidade, ela faz aparecer

... uma medida objetiva da eficácia, do esforço e da vitória: o montante do ganho. Vencer não era, portanto, uma questão de apreciação pessoal e de "qualidade de vida”; era mensurável pela quantidade de dinheiro ganho, pela fortuna acumulada. A quantificação fazia surgir um critério irrecusável e uma escala hierárquica que não precisavam ser validadas por nenhuma autoridade, nenhuma norma, nenhuma escala de valores. A eficiência era mensurável e, através dela, a capacidade de um indivíduo, sua virtude: mais vale mais que menos, aquele que consegue ganhar mais vale mais que aquele que ganha menos (Gorz, 2003, p. 113).

Na essência dessa nova lógica está o fato de que a medida quantitativa "não admite nenhum princípio de autolimitação" (Gorz, 2003, p. 113), ignora não apenas a categoria do "suficiente", mas também aquela do "excesso". Procedendo assim, "eliminava qualquer critério que permitisse satisfazer-se com o que se possui, com o que se fez, com o que se projetava fazer" (Gorz, 2003, p. 113) e, por conseguinte, leva a sociedade como um todo a substituir o antigo princípio do "isso me basta" pelo novo princípio do "quanto mais, melhor" (Gorz, 2003).

As consequências logo se farão sentir. A crescente produção de mercadorias caminha lado a lado com o seu necessário consumo, que passa a estar a serviço da produção, e não o contrário. As necessidades de consumo deveriam crescer pelo menos tão rapidamente quanto o aumento da produção de mercadorias (Gorz, 2003). "A eficiência ilimitada na valorização do capital exigia assim o máximo ilimitado de ineficiência na provisão das necessidades e de desperdício no consumo" (Gorz, 2003, p. 115), o que abre margem para uma série de análises críticas de Gorz sobre a questão do consumo e do consumismo. Nesse autor, encontramos uma crítica radical do modelo de consumo, sempre vinculada à crítica do modelo de produção, o que, por sua vez, entrelaça economia, sociedade e natureza.

O sucesso da ideologia do progresso ilimitado, do "crescimentismo", consiste na capacidade que o sistema capitalista tem para alavancar indefinidamente o consumo de mercadorias. Para isso, vale-se de algumas estratégias que incluem o recurso à propaganda (travestir as mercadorias de símbolos), ao aumento da obsolescência dos produtos, à substituição dos consumos e serviços coletivos por consumos e serviços individuais, entre outros (Gorz, 1978, 2010; Latouche, 2009).

Ironicamente, embora o capitalismo industrial, em sua época, tenha superado dois grandes limites - transformar o trabalho em mercadoria, o trabalho concreto em trabalho abstrato e vencer as barreiras do suficiente -, atualmente, o capitalismo financeiro defrontase com um novo e insuperável limite: o de que sua ânsia de crescimento indefinido esbarra em um limite externo, que é o limite imposto pela disponibilidade dos recursos naturais na proporção, no volume e na velocidade desejados (Gorz, 1978, 2010), o que deflagra a crise de reprodução desse sistema com a natureza, conforme vimos anteriormente.

Um dos objetivos de Gorz é chamar a atenção para a irracionalidade do que se entende por racionalidade econômica. O capital se autonomiza em relação às necessidades reais das pessoas e passa a girar em um circuito que vive para si e não mais para as sociedades a serviço das quais deveria estar (Polanyi, 
2000). Na perspectiva da lógica contábil, o que vale é o crescimento do PIB, mesmo que isso se dê à custa de "empregos" que não fazem sentido para aqueles que os "têm", da falta de saúde ou mesmo da destruição da natureza. O importante é o crescimento da produção e do consumo de mercadorias. "O sistema só poderia mesmo crescer e se reproduzir ao acelerar a destruição e, ao mesmo tempo, a produção de mercadorias" (Gorz, 2010, p. 52).

\section{PERSPECTIVAS: "é preciso ousar o êxodo"}

Por isso mesmo, "a racionalidade econômica deve ser limitada” (Gorz, 1999, p. 89), o que se constitui em uma gigantesca obra de imaginação teórico-prática para a qual Gorz também contribui.

É preciso aprender a discernir as possibilidades não cumpridas que dormitam nas dobras do presente. É preciso querer apropriar-se daquilo que se transforma. É preciso ousar o Êxodo. [...] É preciso aprender a enxergar, por detrás das resistências, das disfunções, dos impasses de que é feito o presente, os contornos dessa outra sociedade (Gorz, 2004, p. 9).

Temos a convicção de que o conceito de racionalidade econômica, embora tematizado 乞ิ tardiamente - Gorz o faz apenas em $1988 \mathrm{em}$ i Metamorfoses do Trabalho -, é central em sua análise do sistema capitalista. E analisa tamڤं bém suas consequências tanto para a questão \& do trabalho como para a questão do ambiente. São dois campos que foram objeto de refle¿ xão e produção ao longo de sua vida (Langer, 2007). Além disso, Gorz recusa-se a permanecer apenas na análise, embora crítica, do capi- talismo. Ele canaliza parte de sua energia para pensar saídas, que têm em comum o fato de requererem a limitação da racionalidade econômica, condição básica e fundamental do seu horizonte utópico. Nos limites deste artigo, apresentamos algumas perspectivas avançadas por Gorz.
Uma primeira perspectiva centra-se na autolimitação das necessidades. Gorz está convencido da necessidade de fazer esse debate. Ao mesmo tempo, sabe que essa é uma questão extremamente complexa. Ele parte da constatação de que "todas as necessidades e desejos são necessidades e desejos de mercadorias, ou seja, necessidades de dinheiro. Nós produzimos a riqueza em dinheiro, que, por sua essência abstrata e sem limites, dá origem a necessidades igualmente sem limite" (Gorz, 2010, p. 60). A ideia do "suficiente" - "ideia de um limite para além do qual nós produziríamos e consumiríamos demasiadamente" - "não pertence à economia nem à imaginação econômica” (Gorz, 2010, p. 60), exatamente por ser uma categoria estranha à lógica da racionalidade econômica. Gorz conserva a capacidade de reinserir a discussão no social, no político, no cultural.

Como as necessidades têm algo de relativo, seus limites não podem simplesmente ser impostos, ou sua satisfação se dar pelo acesso ao poder econômico. "Não existe nenhuma norma comumente aceita do suficiente que possa servir de referência à autolimitação. E, no entanto, esta continua a única via não autoritária, democrática, para uma civilização industrial ecocompatível” (Gorz, 2010, p. 36). A norma do suficiente, "na falta de uma base tradicional, deve ser definida politicamente" (Gorz, 2010, p. 37). A autolimitação das necessidades requer um ambiente de "supressão da alienação" (Gorz, 1991, p. 36) e de retomada da utopia, outro tema caro a Gorz.

Ao contrário do que propõe o capitalismo, recorrendo ao uso de uma carga asfixiante de propaganda e publicidade, as "necessidades poderiam ser mais bem satisfeitas por um fluxo menor de produtos, melhores e mais duradouros [...]. Nós poderíamos viver e trabalhar menos e consumir menos, na condição de consumir de outra maneira” (Gorz, 1991, p. 172). Mas isso implica uma mudança de paradigma, que pode ser resumida na divisa "menos, mas melhor" (Gorz, 1991, p. 172). 
A perspectiva ética e antropológica subjacente remete a conceitos apagados e esquecidos pela racionalidade econômica, o que induz a uma "religião do crescimento" (Gorz, 2010, p. 30). A mudança do modo de vida assenta-se sobre novas bases. Para se contrapor à lógica dominante do "consumo opulento", já existem, em nossas sociedades, experiências e construções teóricas que põem em movimento a lógica da sobriedade, da frugalidade, da simplicidade, da gratuidade. São todas maneiras de dizer "isso me basta" e que partem não de uma imposição autoritária, mas são livremente escolhidas.

À luz desse horizonte, compreende-se melhor a adesão de Gorz ao "decrescimento", que, na sua concepção, significa produzir menos mercadorias. Serge Latouche, economista francês simpático e continuador das ideias de Gorz, endossa essa posição de seu colega francês, pois a "sociedade de crescimento não é sustentável nem desejável" (Latouche, 2006, p. 2). O decrescimento deve ser entendido como necessariamente anticapitalista. Pois, como o crescimento e o desenvolvimento são crescimento da acumulação do capital e desenvolvimento do capitalismo, "o decrescimento é obrigatoriamente um decrescimento da acumulação, do capitalismo, da exploração e da predação" (Latouche, 2009, p. 128) e, por conseguinte, "implica ao mesmo tempo redução quantitativa e transformação qualitativa do trabalho" (Latouche, 2009, p. 117). Ele representa um "imperativo de sobrevivência. Porém, ele supõe uma outra economia, um outro estilo de vida, uma outra civilização, outras relações sociais" (Gorz, 2010, p. 17). Por isso, o decrescimento é uma "boa ideia", pois "convida a imaginar como viver melhor consumindo e trabalhando menos e de maneira diferente" (Gorz, 2010, p. 57).

O decrescimento da produção de mercadorias e de serviços mercantis deverá ser realizada graças a uma autolimitação das necessidades compreendida ela mesma como uma reconquista da autonomia, isto é, graças a uma reorientação democrática do desenvolvimento econômico, com redução simultânea da duração do trabalho e extensão, favorecida pelos equipamentos coletivos ou comunitários, das possibilidades de autoprodução cooperativadas ou associativas (Gorz, 1991, p. 38-39).

Podemos imaginar as resistências que uma política de sociedade assim concebida enfrenta em um contexto em que o crescimento econômico - muitas vezes desvinculado do desenvolvimento geral - é um imperativo categórico de sobrevivência, e de como constitui um desafio de difícil aceitação, inclusive para setores da esquerda.

Uma segunda perspectiva diz respeito ao lugar social concedido ao trabalho. Uma das questões centrais do pensamento de Gorz diz respeito à análise crítica do trabalho. Diz ele:

É preciso ousar o êxodo da 'sociedade do trabalho': ela não existe mais e não será mais restabelecida. [...] É preciso que o "trabalho" perca sua centralidade na consciência, no pensamento, na imaginação de todos. É preciso aprender a vê-lo sob um outro olhar: não mais pensá-lo como algo que possuímos ou não possuímos, mas como algo que fazemos. Precisamos ousar e desejar recuperar a apropriação do trabalho (Gorz, 2004, p. 9).

A peculiaridade de sua abordagem consiste em delimitar o que se entende por trabalho economicamente racional. O trabalho racional, no sentido econômico, de acordo com Gorz, deve preencher quatro requisitos:

a) criar valor de uso;

b) ter em vista uma troca comercial;

c) ser realizado na esfera pública;

d) ter o tempo como critério de medida da produtividade (Gorz, 2003).

O autor defende que "não basta que uma atividade seja empreendida em vista de sua troca mercantil (de sua remuneração) para que ela seja trabalho no sentido econômico" (Gorz, 2003, p. 137). Ele está na contramão da grande maioria ao propor não uma extensão das atividades englobadas pela noção de trabalho no sentido econômico, mas uma delimitação (Langer, 2007). Ao invés de entregar atividades à lógica do capital, procura arrancá-las dela. 
Por trás disso está um determinado projeto de sociedade.

Gorz propõe duas políticas: a primeira diz respeito à diminuição do tempo de trabalho, com vistas a partilhar, entre todos, o trabalho social necessário e aumentar o tempo livre, dedicado ao exercício de atividades não necessariamente econômicas, mas criadoras de relações sociais e cheias de sentido (Gorz, 2004); a segunda diz respeito à defesa incondicional da renda universal de existência (Gorz, 2004, 2005; Langer, 2004). A renda garantida deve tornar possíveis, segundo Gorz, todas "as atividades fora do mercado, fora de compatibilidade e fora de normas, e que não são e não produzem nada de permutável por outra coisa, nada de mensurável e de traduzível em seu equivalente monetário" (Gorz, 2005, p. 75). Baseia-se mais em critérios antropológicos do que econômicos.

Entrelaçada com essa perspectiva está a ecologia política. "O reequilíbrio entre trabalho remunerado, de um lado, atividades não remuneradas e lazeres, de outro, é particularmente importante na perspectiva de uma reestruturação ecológica da sociedade” (Gorz, 1991, p. 169), porque há uma relação entre o tempo dedicado ao trabalho remunerado e a tendência ao consumo de mercadorias. Inversamente, "a autolimitação da duração do trabalho, o 'tempo escolhi\o’ torna possível a autolimitação da renda e do సे consumo mercantil, segundo as necessidades e ¿ os desejos realmente sentidos por cada pessoa" (Gorz, 1991, p. 170). Consequentemente, "o imperativo ecológico exige um decrescimento da economia, mas esse decrescimento não exige necessariamente sacrifícios, mas renúncias" (Gorz, 1991, p. 171, grifo do autor).

Uma ecologia política implica "uma mudança de paradigma”, que Gorz resume na divisa "menos, mas mais" (Gorz, 1991, p. 172), que se contrapõe à divisa capitalista de "produzir mais, consumir mais"... Ela tem em vista "reduzir a esfera na qual a racionalidade econômica e as trocas mercantis são desenvolvidas e colocar a serviço de fins societários e culturais não quantificáveis, a serviço do livre desenvol- vimento dos indivíduos” (Gorz, 1991, p. 173).

Mas Gorz cedo percebeu que o capitalismo, dada sua capacidade de resiliência, poderia assimilar a pressão ambiental e incorporá-la com vistas a seus interesses, tirando proveito, inclusive, da destruição da natureza. Por isso, em um artigo publicado originalmente na revista Le Sauvage, em 1974, e depois incorporado ao livro Écologie et Politique, fala na ecologia "deles", contrapondo-a à "nossa", com objetivos e fins diversos. Ali ele insiste na necessidade de opor à divisa da sociedade capitalista, à "ideologia do crescimento" - "Aquilo que é bom para todos não vale nada. Você só será respeitado se for 'melhor' do que os outros” -, esta outra, uma divisa ecológica - "Só é digno de você aquilo que é bom para todos. Só merece ser produzido o que não favorece nem diminui ninguém” (Gorz, 1978, p. 14).

Nesse sentido, a ecologia política deve necessariamente ser anticapitalista e socialista.

Para viver melhor, é preciso daqui em diante produzir e consumir de outra maneira, fazer melhor e mais com menos, eliminando, para começar, as fontes de desperdício (exemplo: as embalagens perdidas, o mau isolamento térmico, a prevalência do transporte rodoviário, etc.) e aumentando a durabilidade dos produtos (Gorz, 1991, p. 194).

Por essa maneira de ser e de pensar de Gorz, a sociedade socialista continua a estar no horizonte de suas utopias; mas o conteúdo do socialismo precisa ser repensado, alargado, ressignificado, pois esse sistema "não é melhor que o capitalismo se ele recorre aos mesmos instrumentos. A dominação total do homem sobre a natureza entranha inevitavelmente uma dominação do homem pelas técnicas de dominação" (Gorz, 1978, p. 28). Pelo contrário, o socialismo deve ser "a resposta positiva à desintegração dos laços sociais sob o efeito das relações mercantis e da concorrência, características do capitalismo" (Gorz, 1991, p. 87).

Recebido para publicação em 05 de junho de 2017 Aceito em 28 de julho de 2017 


\section{REFERÊNCIAS}

ARENDT, H. A condição humana. 4. ed. Rio de Janeiro: Editora Forense Universitária, 1989.

BEAUD, M. Le Basculement du Monde: de la Terre, des Hommes et du Capitalisme. Paris: La Découverte, 1997.

CECHIN, A. A natureza como limite da economia: a contribuição de Nicolas Georgescu-Roegen. São Paulo: Editora Senac São Paulo: Edusp, 2010.

DE MASI, D. A sociedade pós-industrial. São Paulo: Editora Senac, 1999.

DESCARTES, R. Discurso do método: as paixões da alma meditações; objeções e respostas. 5. ed. São Paulo: Nova Cultural, 1991.

GOLLAIN, F. Une critique du travail: entre écologie et socialisme. Paris: La Découverte, 2000.

GORZ, A. Capitalisme, socialisme, écologie: désorientations, orientations. Paris: Éditions Galilée, 1991.

GORZ, A. A crise e o êxodo da sociedade salarial. Cadernos IHU Ideias, São Leopoldo, ano 3, n. 31, p. 1-24, 2005.

GORZ, A. Ecológica. São Paulo: Annablume, 2010.

GORZ, A. Écologie et politique. Paris: Éditions du Seuil, 1978.

GORZ, A. Entretienavec André Gorz. In: GOLLAIN, F. Une critique du travail: entre écologie et socialisme. Paris: La Découverte, 2000. p. 219-242.

GORZ, A. O imaterial: conhecimento, valor e capital. São Paulo: Annablume, 2005.

GORZ, A. Metamorfoses do Trabalho: crítica da razão econômica. São Paulo: Annablume, 2003.

GORZ, A. Misérias do presente, riqueza do possível. São Paulo: Annablume, 2004.
LANGER, A. Os três legados de Gorz. Revista IHU On-Line, São Leopoldo, n. 238, p. 32-36, 2007.

LANGER, A. Pelo êxodo da sociedade salarial: a evolução do conceito de trabalho em André Gorz. Cadernos IHU, São Leopoldo, n. 5, 2004.

LATOUCHE, S. O decrescimento como condição de uma sociedade convivial. Cadernos IHU Ideias, São Leopoldo, n. 56, 2006.

LATOUCHE, S. Pequeno tratado do decrescimento sereno. São Paulo: Martins Fontes, 2009.

MARX, K; ENGELS, F. Manifesto do Partido Comunista. 9. ed. Petrópolis: Vozes, 1999.

MÉDA, D. Le travail: une valeur en voie de disparition. Paris: Aubier, 1995.

MERCURE, D. Adam Smith: as bases da modernidade. In: MERCURE, D.; SPURK, J. (Org.). O trabalho na história do pensamento ocidental. Petrópolis: Vozes, 2005. p. 115-136.

MORIN, E. Ciência com consciência. Rio de Janeiro: Bertrand Brasil, 1996.

MORIN, E. Por uma globalização plural. CEPAT Informa, Curitiba, n. 82, p. 41-48, abr. 2002

OLIVEIRA, Manfredo Araújo de. O paradigma tecnocrático. In: MURAD, A.; TAVARES, S. S. Cuidar da casa comum. São Paulo: Paulinas, 2016, p. 129-145.

POLANYI, K. A grande transformação: as origens da nossa época. 2. ed. Rio de Janeiro: Campus, 2000.

SANTOS, B. S. Introdução. In: SANTOS, B. S. (Org.). Conhecimento prudente para uma vida decente. São Paulo: Cortez, 2004. p. 17-56.

SILVA, J. P. O "Adeus ao Proletariado" de Gorz, vinte anos depois. Lua Nova, São Paulo, n. 48, p. 161-174, 1999.

WEBER, M. A ética protestante e o "espírito" do capitalismo. São Paulo: Companhias das Letras, 2004. 


\section{ECONOMIC RATIONALITY, WORK AND ECOLOGY IN ANDRÉ GORZ}

André Langer

This article's objective is to present André Gorz's critical analysis of work and political ecology starting from the centrality that the concept of economic rationality acquires in his thought. To the author, the unlimited extension of economic rationality to work and nature is considered futureless from the viewpoint of society. Gorz recognizes the intimate relationship between criticism of capitalism and the task of political ecology. Another aspect present in his work - the least explored one - is the relationship between work and ecological crisis. Capitalism appropriates work or employment not just for its interests, but also for transforming them into instruments of environmental destruction. This paper also aims to indicate - following the spirit of Gorz, although in a succinct manner - a few alternative horizons.

KEywords: Gorz. Economic rationality. Labor. Mots-clés: Gorz. Rationalité économique. Travail. Political ecology. Capitalism.

\section{RATIONALITÉ ÉCONOMIQUE, TRAVAIL ET ÉCOLOGIE CHEZ ANDRÉ GORZ}

André Langer

L'objectif de cet article est de présenter l'analyse critique d'André Gorz sur le travail et l'écologie politique. Notre point de départ est la centralité que le concept de rationalité économique dans le capitalisme acquiert dans sa pensée. Selon lui, l'extension illimitée de la rationalité économique au travail et à la nature est considéré sans avenir du point de vue de la société. Gorz reconnaît l'étroite relation existante entre la critique du capitalisme et la tâche de l'écologie politique. Un autre aspect présent dans son œuvre, et beaucoup moins exploré, est la relation entre le travail et la crise écologique. Le capitalisme s'approprie le travail ou l'emploi non seulement pour les soumettre à ses intérêts mais aussi les transforme en instruments de destruction de la nature. Cet article veut aussi, bien que de manière succincte mais fidèle à l'esprit de Gorz, donner quelques alternatives pour de nouveaux horizons.

Ecologie politique. Capitalisme. salarial. A evolução do conceito de trabalho em André Gorz. Cadernos IHU, v. 2, n. 5, 2004. 